\title{
Heart disease and the stress hypothesis in the mid-twentieth century: a historical review
}

Heather L. Rogers ${ }^{1,2}$

\begin{abstract}
Background: In the 1920s, heart disease (a noncommunicable disease), was the new leading cause of death in the USA. Simultaneously, experimental progress in the study of stress provided scientific justification for a new type of risk factor. The objective of the present work is to examine the history of heart disease as a public health problem and the contribution of advancements in scientific knowledge about stress in the 1930s-1960s supporting the hypothesis of stress as one cause of disease.
\end{abstract}

Results: In the process of studying heart disease risk factors in the 1950s, medical practitioners became responsible for the early detection of risk factors in order to "catch" chronic disease in its earliest stage. Coronary heart disease specifically was a disease of white, middle class, professional males, and "stress" was hypothesized as one reason why this population was particularly vulnerable. Walter Cannon and Hans Selye provided experimental evidence that stress might cause physical disease. In the 1930s, Cannon described how the body seeks to maintain homeostasis. When the body's systemic equilibrium is challenged by something dangerous in the environment or an insult directly to the body, the sympathetic nervous system (SNS) and adrenals are stimulated. In the 1940s and 1950s, Selye discovered that a universal triad of stress effects (hypertrophy of the adrenal glands, involution of the thymus and lymphoid tissue, and ulceration in the gastrointestinal tract) was seen repeatedly after any noxious or aversive event (i.e., noise, shock, etc.). The stress responses occurred in a certain pattern, known as the general adaptation syndrome or GAS. Autopsy from Selye's laboratory animals showed that, in addition to the general pathological effects of GAS, arteries were thickened and hardened, just as would be seen in human victims of heart and circulatory disorders.

Conclusions: Since then, large scale, prospective epidemiological studies, meta-analyses, and systematic reviews, as well as smaller scale basic science studies, have established the relationship between stress and heart disease development and progression. Most evidence centers on depression and the biobehavioral mechanisms underlying its contribution to heart disease. However, effective prevention/intervention strategies that improve stress and physical disease outcomes are still needed.

Keywords: Heart disease, Stress, Public health, Risk factor

\section{Introduction}

At the end of the nineteenth century and in the early twentieth century, the prevailing paradigm in medicine was that of etiological specificity of disease. Doctors began to specialize and focus on particular organs or organ systems (Rosen 1975). At the same time,

Correspondence: rogersheatherl@gmail.com

'BioCruces Health Research Institute, Plaza de Cruces s/n, Barakaldo 48903, Vizcaya, Spain

${ }^{2}$ IKERBASQUE Basque Foundation for Science, Maria Diaz de Haro 3, Bilbao 48013, Vizcaya, Spain

\section{Springer Open}

(c) The Author(s). 2016 Open Access This article is distributed under the terms of the Creative Commons Attribution 4.0 International License (http://creativecommons.org/licenses/by/4.0/), which permits unrestricted use, distribution, and reproduction in any medium, provided you give appropriate credit to the original author(s) and the source, provide a link to the Creative Commons license, and indicate if changes were made. 
agent was no longer sufficient to explain these new diseases. A new, multicause risk factor paradigm was needed. Meanwhile, experimental progress in the study of stress provided scientific justification for a new type of risk factor. The objective of the present work is to examine the history of heart disease as a public health problem and the contribution of advancements in scientific knowledge about stress in the 1950 s and 1960s supporting the hypothesis of stress as one cause of disease.

\section{Review}

\section{History of heart disease as a public health problem}

According to the National Center for Health Statistics (1998), ${ }^{1}$ the top two leading causes of death in the USA from 1901 to 1907 were pneumonia and tuberculosis. Heart disease ranked third. In 1908 and 1909, heart disease became the second leading killer. In 1910, it became the leading cause of mortality until 1918 when it dropped back second, behind pneumonia and influenza. In 1921, heart disease again became the leading cause of death and remained so through 1975 and beyond. ${ }^{2}$

In search of a reason for this rise in coronary deaths after 1920, some authors argued that the increase was due primarily, and possibly entirely, to saving the lives of those who would have died of other diseases prior to the great improvement in overall mortality trends after 1880 (e.g., Campbell 1963a, 1963b, 1964). With fewer deaths from communicable disease, people lived longer. In fact, the hypothesis in the 1950s was that people were now living long enough to acquire conditions largely limited to older people.

Chronic disease was such a problem by 1950 that certain epidemiologists were concerned that the field of public health would over-emphasize geriatrics and neglect diseases of childhood. Gordon (1952), in his chapter on the Future of American Epidemiology in Franklin H. Top's book The History of American Epidemiology, reminded public health officials of the day that "the greater profit in years of healthful living is alone sufficient reason for greater stress on the mass diseases of childhood.....for the child these are years of productive and creative effort; for the older person they are likely to be not only few but relatively unproductive" (p. 156).

The recognition of heart disease and kidney disease and other noncommunicable diseases as important causes of death in the 1920s and 1930s led public health campaigns to emphasize the importance of early detection. As a result, the necessity of periodic health examinations as preventive measures was advocated by life insurance companies, medical societies, health departments, and voluntary health agencies (Rosen 1975). However, the diagnosis of various heart diseases (e.g., angina pectoris, coronary artery disease) was difficult.
Scientific advancements in the detection of heart disease Scientific advancements in the objective detection of disease markers did not occur until the late 1950s. For example, the ballistocardiograph and electrocardiograph were used to measure electrical activity in the heart following exercise (vs. at rest) as a more objective means for detecting coronary atherosclerosis (Davis 1959). Scientists of the day understood that blood from the heart is ejected upwards, along the ascending aorta, and when pulling blood into the heart, the major motion is also along the axis parallel to the spine. Using Newton's third law, the force exerted on the blood by the heart is matched by an equal and opposite force on the body by the blood. The force is longitudinal. Scientists thought that if a patient is placed on a table with very low friction, then the force on the body causes the body and the table to move back and forth as the blood is being pumped. A sensitive accelerometer on the table could then measure its acceleration. The acceleration of the blood was computed using a ballistocardiogram (American Heritage Dictionary of the English Language 2006). Although recent advancements have improved this technique and it is still used today, because the mass of the accelerating blood is small compared to the mass of the body and table, the experimental errors in the measured blood acceleration in the 1950s were large. Thus, it was not very useful as a diagnostic tool. ${ }^{3}$ Regardless, Davis (1959) also suggests ballistocardiogram recording after smoking a cigarette or after injection of potent vasoconstrictors like ergonovine and pitressin as promising, yet cautious, endeavors. Moreover, there was evidence that the ballistocardiogram recording before and after a heavy meal ${ }^{4}$ may provide additional means of proving the presence of coronary artery disease (Buff 1959).

\section{Policy decisions and early epidemiological study of heart disease}

In 1964, the Report of the President's Commission on Heart Disease, Cancer and Stroke (1964) was published. This report proposed "the establishment of a national network of Regional Heart Disease, Cancer and Stroke centers for clinical investigation, teaching and patient care, in universities, hospitals and research institutes and other institutions across the country" (p. 29). Medical practitioners were concerned that the regional medical centers would be dominated by academic medicine. These objections caused legislation to be passed in 1965 that authorized cooperative agreements between health care institutions, medical schools, and research establishments as the means for making the best diagnostic and therapeutic care available to patients with heart disease, cancer, or stroke (Rosen 1975). 
Prior to this report, epidemiological approaches were beginning to be applied to the study of heart disease. The Framingham Heart Study (Dawber et al. 1951) was initiated immediately after World War II in 1948 by the U.S. Public Health Service. Assistant Surgeon General Joseph Mountin, M.D., conceived the idea of the study. Gilcin F. Meadors, M.D., was a young Public Health Service officer in charge of organizing the study. In that year, the National Institutes of Health was expanded to encompass several institutes, each devoted to the study of particular diseases. First, the National Cancer Institute was founded, followed by the National Heart Institute in 1949. The administration of the Framingham Heart Study was then transferred to the Heart Institute, known today as the National Heart, Lung, and Blood Institute.

The Framingham study began with a cohort of 5209 healthy men and women between 30 and 60 years of age who were residents of the town of Framingham, MA. Framingham had been the location of a 1918 study on tuberculosis and was an ideal location because of its proximity to Boston's major medical centers, the presence of several large employers (e.g., General Motors and Dennison Manufacturing ${ }^{5}$ ), and the support of a well-informed, highly cooperative medical community. The study was novel in many ways in that it (1) sought to study noninfectious disease, for example, heart disease and stroke, (2) included both men and women participants, and (3) examined the relationship between lifestyle and disease (Dawber 1980). In the first 30 years of the study, scientists used clinical observations and early diagnostic tests such as the electrocardiogram and the chest $\mathrm{x}$-ray. As the disease developed, they made careful observations and counted events. After an event, they attempted to determine what those individuals with the disease had in common and how they differed from others who remained disease-free. For example, after 4 years, there were 34 cases of heart attack, which investigators determined were associated with high cholesterol, high blood pressure, obesity, and electrocardiogram abnormalities (Dawber et al. 1957).

In the late 1940s, the public perception of illness was often viewed as an accident. Individuals who developed heart disease or cancer were considered unlucky. Disease was beyond individual control and could not be caused or prevented anymore than an accident. The Framingham study coined the term "risk factor," implying that multiple factors may influence a disease state and also that individuals were empowered to impact their health. The paradigm shift that occurred as researchers and practitioners moved from a single agent model of causality to a multiple risk factor model in which independent causes may work synergistically to contribute to disease states is beyond the scope of this paper.
In the process of studying heart disease risk factors in the 1950s, medical practitioners gained a new responsibility for not only treatment but also early detection of risk factors in order to "catch" disease in its earliest stages. However, it is important to note that, even in 1975, not all researchers agreed that changing behavior could lower the risk of coronary heart disease. Morris (1975) argued that "there is no proof in the conventional sense that by altering behavior in accord with the results of observational studies with have been carried out controlling weight, abandoning cigarettes, taking adequate exercise, or lowering blood pressure and lipid values in middle age - individual risk and population incidence will be lowered." (p. 73).

Since the Framingham study, cardiovascular epidemiology has tended to focus mainly on individual risk factors, as opposed to environmental or social contributors to these diseases. The principle of sampling was representativeness, and the unit of sampling was the individual person. As a result, the unit of analysis also became the individual person and all the risk factors became individual. Kristensen (1999) argues that this research tradition agreed well with the prevailing American individualist and liberalistic tradition but consequently, little effort has been paid to the social, economic, and occupational factors that may underlie the individual risk factors. This tradition is also sometimes criticized for "victim blaming" and for ignoring class differences and living conditions.

Social, economic, and occupational influences on the development of heart disease were noted as early as the late 1940s when Dublin et al. (1947) reported that, compared to the general male population of similar age, doctors were 1.18 times more likely to die of heart disease. Stewart (1950), a member of the British Royal Army Medical Corp, states that "it seems to be beyond dispute that the better educated, and those who work with their brains, are more liable than their fellows to coronary disease" (p. 1105). This view was disputed by Platt (1951), who questioned the accuracy of the death certificates based on the likelihood that a person dying would have seen a consulting physician or cardiologist who could make the diagnosis of coronary heart disease. Platt argues that the "difference is not one of disease but of nomenclature" (p. 1108).

Retrospective examination of mortality data from the 1940s and 1950s show that mortality due to hypertensive heart disease declined, with a steeper rate of decline in the early 1950s. The rate of decline was steeper for whites compared to nonwhites. Although the decline after the 1950 s can be partially explained by the development and use of drugs that effectively lowered blood pressure (i.e., hexamethonium, hydralazine, rauwolfia, and methyldopa), the reason for the decline previous to 
1950 was unknown as of 1975 (Rosen 1975). Some authors (e.g., Moriyama et al. 1971) suggested that the differential rates may be explained by socio-economic factors, including inadequate medical care. Later in the century, coronary heart disease, a very specific type of heart disease, was indeed found to be associated with the working class, instead of the middle class, and socioeconomic disadvantage (Marmot et al. 1978). The social gradient observed in the late 1940 s by Stewart and others was reversed, yet the proposed mediating mechanisms have remained the same (Macleod and Smith 2002).

\section{Mediating mechanisms linking white, middle class males to heart disease: stress}

By the 1950s, it was clear that not all segments of society were equally affected by heart disease. In an examination of socio-economic status, Stewart (1950) reported figures from the Registrar General's Decennial Supplement in which the adult population was divided into five classes based on occupation and income levels which have recently become more closely correlated. Class 1 consists of the professional workers and class 5 represents the unskilled laborers. Stewart (1950) asserted that "the proportion of deaths from coronary disease is well above average in the first two classes, and well below it in the last three" (p. 1104). Moreover, Stewart (1950) recognized that women appeared to be immune, further perpetuating the notion that coronary heart disease was a disease of white, middle class, professional males. When considering why this particular population may be vulnerable to heart disease, Stewart (1950) postulates that "these people are exposed to a particular form of stress" (p. 1105) and suggests that the "selectivity of the pathological change is the kernel of the problem" (p. 1105).

The hypothesis that stress might cause physical

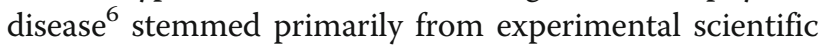
research from American physiologist Walter B. Cannon (1871-1945) and Austrian-born Canadian endocrinologist Hans Selye (1907-1982).

\section{Homeostasis and the fight or flight response of the body to threat}

At the turn of the century, although a vital bodily function, scientists knew very little about the mechanics of digestion. Cannon devised means of employing the newly developed Röntgen ray, or $\mathrm{x}$-ray, to study digestive processes uninhibited by surgical or mechanical intervention. Among other accomplishments in describing the digestive processes of animals in his lab, Cannon observed that any change of emotional state in the animal (e.g., anxiety, distress, or rage) was accompanied by total cessation of movements of the stomach. Additional attention to the effects of emotions on digestive organs led him to explore the autonomic nervous system which controls these movements (Benison et al. 1987).

The demands of World War I interrupted Cannon's work. He went to Europe with a Harvard medical unit whose duty it became to study and to combat shock. After returning to both research and teaching, he became one of the pioneers in the study of the autonomic nervous system. Cannon identified the sympathetic nervous system's emergency reaction, which prepared the body to exert high levels of physical energy. He isolated a chemical product, sympathin, an epinephrine-like substance found at terminals of nerves, and described its role as mediator of impulses between the nerve and the muscle. Cannon studied the function of adrenal glands and the effects of their secretions on the body, especially under conditions of stress or excitement. His observations convinced him that the living body always strives towards a harmonious equilibrium, a state which was referred to as "homeostasis" in the book, The Wisdom of the Body, and in other writings (Cannon 1932). This concept paralleled the milieu interne (internal environment) notion advanced earlier by Claude Bernard.

According to Cannon (1932), the body seeks to maintain homeostasis. When the body's systemic equilibrium is challenged by something dangerous in the environment or an insult directly to the body, the sympathetic nervous system (SNS) and adrenals are stimulated. The result of such stimulation is an increase in heart rate and contractility, constriction of blood vessels, and dilation of bronchioles and pupils. This reaction allows the aroused organism to confront or flee the danger; thus, the response became known as the fight or flight response. Cannon believed that the SNS and adrenals also played a key role in returning the body to its normal state of equilibrium after such arousal had occurred.

\section{The physiological stress reaction as a cause of disease}

Hans Selye was an Austrian-born endocrinologist who received his M.D. and Ph.D. from the German University of Prague. In 1925, as a first-year medical student, he was taught to recognize a specific disease and the germ that caused it. However, Selye believed that his professors overlooked the general symptoms that were common to all sick men and women he encountered-pallor, fatigue, aching bones and joints, fever, and loss of appetite and weight. Selye observed that people, whether they had specific diseases like tuberculosis, pneumonia, or scurry, seemed to have the same nonspecific disease too. What about the general feeling of being sick? His clinical professors told him not to bother with such things and Selye put these clinical observations, and the idea of an underlying common cause, aside for the time being (Ratcliff 1955). 
In 1931, Selye won a Rockefeller fellowship to study at Johns Hopkins University Medical School in Baltimore, MD. The next year, he went to McGill University in Montreal, Canada, to teach biochemistry. By 1936, two female sex hormones had been identified and Selye thought he was about to discover a third. To test the effects of a new extract from the ovary, he injected it into female rats whose ovaries had been removed. Upon sacrifice of the animal, he expected to see changes in the animals' sexual organs. Instead, he found enlarged adrenal glands approximately three times their normal size, shrunken thymus glands and lymph nodes, and ulcerated stomachs and intestinal tracts. Selye injected material from other organs and observed the same effects. He wondered if his material was toxic and injected formaldehyde to test this theory. Again, he observed the same pattern postmortem. He knew he had failed in discovering a new hormone and had two choices-to abandon this line of research or find a new way to examine his data. Selye recalled his clinical experiences in medical school and the common symptoms of his patients at the hospital in Prague. He theorized that those patients and their feelings of just being sick had something in common with his sick laboratory animals. He theorized that his serendipitous discovery of swollen glands, degenerated lymphatic systems, and ulcerated stomachs in the lab might be a single, nonspecific reaction of the body to damage of any kind, leading to clinical manifestations that corresponded to this nonspecific disease (Selye 1979). Moreover, Selye knew that certain medical treatments (like rest, eating food that was easy to digest, and protection against extreme temperatures) could be useful to patients suffering from many aliments. He also knew that many nonspecific treatments in the history of medicine (such as fever therapy, shock therapy, and bloodletting) were considered successful, although sporadically, in improving many conditions.

Taken together, Selye theorized that there was some mechanism in the body that would respond to aversive agents in a general fashion. With the help of an assistant, Selye began to experiment with different laboratory animals, from rats to guinea pigs and rabbits. He exposed them to prolonged cold and heat, noise, bright lights, and motor-driven revolving cages. He was forced to use the wind-swept, flat roof of the McGill medical building in winter time, as he lacked a suitably ventilated cold room. In each case, the symptoms appeared (Newsweek, December 3, 1956).

Selye (1956) found that different types of direct bodily insult (e.g., injection of pathogens and various biochemicals, application of heat or cold, exercise, exposure to $\mathrm{x}$-rays) produced hypertrophy of the adrenal glands, involution of the thymus and lymphoid tissue, and ulceration in the gastrointestinal tract. This universal triad of stress effects was seen repeatedly after any noxious or aversive event (i.e., noise, shock, etc.). "Any activity, any emotion, from crossing a busy street to exposure to drafts, or even sheer joy, is enough to set the adrenal glands spurting and so activate the body's stress mechanism." (Newsweek, December 3, 1956, p. 56). Therefore, Selye defined stress as a nonspecific set of specific physiological responses and emphasized the importance of one particular adrenal hormone of the 30 that had been identified-desoxycorticosterone (DCA)-as critical in the adaptation of the body to noxious stimuli. The stress responses occurred in a certain pattern that involved three distinct stages, which Selye called the general adaptation syndrome or GAS.

In the first stage, the alarm stage, adrenocorticotropic hormones (ACTH) (not discovered until 1949) are secreted from the anterior pituitary, which cause the adrenal cortex to release corticosteroids. Hormone output from the adrenal cortex increases rapidly during this stage as the body prepares to resist the noxious stimuli. Selye agreed with Cannon that epinephrine did have a role in the stress response but chose to focus on the adrenal cortex as a key system involved in adaptation. In the second stage of GAS, resistance, the organism resists or attempts to adapt to the noxious stimuli. The output of corticosteroids remains high, but stable, during this stage. By the end of the resistance stage, there is usually an improvement or disappearance of symptoms. If the noxious stimuli are prolonged or sufficiently severe, the last stage of GAS, exhaustion, occurs. In this stage, the body can no longer resist or adapt to the noxious stimuli. Adaptive reserves are depleted. The anterior pituitary and the adrenal cortex lose their capacity to continue to secrete hormones, and symptoms reappear. If the noxious stimuli continue, vulnerable organs may break down (Ratcliff, 1955).

In fact, autopsy from Selye's laboratory animals showed that, in addition to the general pathological effects of GAS on the body, arteries tended to be thickened and hardened and kidneys were severely damaged. Some had arthritis-like diseases and other had diseases similar to rheumatic fever. Their insides looked like those of human victims of heart and circulatory disorders (Selye 1975).

Selye was interested in hormones. He injected large amounts of DCA into his animals. In a short time, they developed heart and kidney disease and high blood pressure. Their joints became swollen, inflamed, and sensitive. In determining which pituitary gland hormone might produce these symptoms, he examined the somatotropic hormone (STH, growth hormone). When injected in excess, it produced a sickness like rheumatic fever, heart and artery disease, and diabetes. The results were reported in The Journal of the American Medical 
Association in 1944, 5 years before the discovery of $\mathrm{ACTH}$ and cortisone. Cortisone was a single medicine that appeared to be effective in a whole range of seemingly unrelated diseases: gout, asthma, skin aliments, arthritis, muscular diseases, and eye diseases. From Selye's perspective, ACTH and cortisone restored the chemical balance. The organism returned to physiological homeostasis, and the disease magically melted away (Selye 1975, 1979).

\section{Conclusions}

Today, it is clear that Selye's description of GAS was not entirely accurate. However, at the time, "stress" was appropriately vague and nonspecific enough to be hypothesized to cause heart disease in the white, middle class professional male population of the 1950s. Interestingly, "stress" is still used today as a mechanism to explain why individuals with lower socio-economic status are at higher risk for heart disease in the twenty-first century.

In the 1950s, numerous scientific research articles highlighted the importance of emotions on heart attack, sudden cardiac death, and congestive heart failure (e.g., Chambers and Reiser 1953). However, the link between thoughts/emotions and the physiological stress response would not be scientifically evidenced for approximately another 25 years. First, science had to discover that the hypothalamus, an organ that was clearly located in the brain, ${ }^{7}$ controlled the physiological stress response via release of corticotrophin releasing hormone (CRH) to the anterior pituitary (Fink 1981). John W. Mason, M.D., a psychoendocrinologist, attempted to re-conceptualize stress, even before this discovery. He suggests that stress is primarily a psychological rather than physiological phenomenon; thus, an organic response is secondary to the psychological one (Mason 1968). Mason (1975) also argued against the nonspecificity concept of Selye's stress theory, suggesting experimental manipulation and clarification of stress terminology.

In the late 1950s, the idea of stress was merging with psychological constructs like tension. The December 3, 1956, issue of Newsweek described Hans Selye's "New Approach to Tensions" because Selye had just published his book entitled The Stress of Life (Selye 1956), in which he explained his theories about the true origins of disease in terms that the general public could understand. The Reader's Guide to Periodical Literature in 19511953 categorized articles relating to "tension," referring to psychological distress. "Stress" was not a subheading until the 1953-1955 edition. "Strains and stresses" (in addition to "tension") classified the few early public interest articles describing stress on the body. Stress was likened to the physicist's sense of the word-force or pressure on an inanimate object that can be measured up to a breaking point (Time, January 18, 1954). By the
1955-1957 edition, "stress" was a category by itself in the Reader's Guide to Periodical Literature and under "tension"; one would also be referred to the "fatigue" category. In the 1957-1959 edition, "tension" was eliminated as an individual category and readers were referred to the "stress" entries.

In 1966, Richard Lazarus, a psychologist, published his book Psychological Stress and the Coping Process. His work focused on how humans interpret the environment around them. In the appraisal process, humans make automatic, often unconscious, assessments of what is happening and what it means to them, which causes emotion and may lead to the physiological stress response depending on secondary appraisals of their resources to manage the situation (Lazarus 1966).

The consequence is that stress is all around us yet quite ambiguous. It may refer to external stimuli in the environment (e.g., the extreme cold of a windy winter day or the noise of the traffic on a city street) or it may be situational (an argument with a family member or losing one's job and having to pay the mortgage or driving and someone tries to cut you off). Stress can be positive (e.g., the birth of a new child) or negative (e.g., the death of a parent) and acute (e.g., an electric shock) or chronic (e.g., job strain). Moreover, the same term, stress, can be used to describe the mental or physical internal states that result from any of these stimuli or situations. For instance, tension, anxiety, irritation, and anger are all synonyms for stress.

Further, as Mason and Lazarus proposed, individuals can vary widely in how they interpret, experience, and hence respond to a given stimulus. What is stressful to some people may be experienced by others as merely trivial, boring, or even amusing. Determining when a detrimental "stress response" occurs and how to uniformly measure it are two facets that make this new paradigm of research concerning stress and disease so difficult. To further complicate matters, genetic differences, earlier experiences, education, etc. are likely to also contribute to disease and there is a long period of time between exposure and disease outcome.

Today, in the twenty-first century, are we any closer to an answer to the question is stress a cause of heart disease? Do we know more than we knew in the midtwentieth century? Still today, psychology, physiology, and public health research fields are often separate areas of investigation. For over a hundred years, tension was thought to cause mental disorders, but not affect physical disease states. In 1957, U.S. News and World Report interviewed Edward Jacobson regarding a new stress relaxation technique called progressive muscle relaxation. Any possible public health benefit that might have resulted from the use of this technique (or other psychological interventions) at the time in preventing chronic 
physical diseases such as heart disease was lost because the scientific evidence that fits nicely into medical paradigm was not, and some would argue still is not, available.

Large scale, prospective epidemiologic studies, metaanalyses, and systematic reviews, as well as smaller scale basic science studies, have established the relationship between stress (and depressive symptoms in particular) and heart disease development and progression. For instance, a scientific statement from the American Heart Association in 2014 concluded that a preponderance of evidence supports depression after a heart attack as a risk factor for death and nonfatal cardiac events (Lichtman et al. 2014). Largely as a result of multidisciplinary training in cardiovascular behavioral medicine, many researchers are now equipped with a strong background in scientific methods and knowledge of advancements in human physiology, heart disease processes, and psychology. Their research examines biobehavioral mechanisms underlying this relationship. Stress, and depression specifically, is associated with traditional risk factors for heart disease such as hypertension, diabetes, and insulin resistance, as well as changes in platelet reactivity and inflammatory responses, and autonomic nervous system and hypothalamic pituitary adrenal axis dysregulation. Behavioral factors associated with stress are also risk factors for heart disease, such as smoking, heavy alcohol use, sedentary behavior, and poor adherence to medical recommendations. However, randomized controlled trials of medication and nonpharmacologic treatments for depression have not demonstrated improved survival. (See review in Wang et al. 2011.)

Thus, still today, the development of prevention and intervention strategies that will improve stress and simultaneously improve outcomes in heart disease is sorely needed. To accomplish this goal, professionals in the medical, psychological, and public health fields can no longer work separately approaching these problems from their individual paradigms. Health professionals must do more than collaborate together in working groups. More researchers in more countries need multidisciplinary training in order to advance the field and further our understanding of the link between psychosocial factors and chronic disease. Scientific and medical breakthroughs must translate into health policies and population-level prevention strategies so that, by the end of the current century, chronic diseases such as heart disease are no longer leading causes of death. Successful prevention measures helped control communicable diseases at the turn of the twentieth century. The challenge for twentyfirst century health professionals is to control chronic diseases as well. Research and implementation science are crucial tools to understand how interventions that might work in one setting might transfer across socio- cultural contexts. The real question is: Are we up for the challenge?

\section{Endnotes}

${ }^{1} 1900-1940$ was data collected from tables ranked in the National Office of Vital Statistics in December 1947.

${ }^{2}$ In 1950, rules for ranking the leading causes of death were developed by NCHS and the states.

${ }^{3}$ Recently, modern signal processing techniques have allowed experimental errors in the ballistocardiogram technique to be greatly reduced, and BCG's are now often used in a medical context according to David M. Harrison, Dept. of Physics, Univ. of Toronto, in July 2003.

${ }^{4}$ The meal consisted of $1 \mathrm{lb}$ of steak, one serving of potatoes, one cup of coffee, and a piece of pie.

${ }^{5}$ Dennison Manufacturing made paper goods and products.

${ }^{6}$ Previous to 1920 , stress, strain, and tension were seen as causes of hysteria and other mental illnesses.

${ }^{7}$ The pituitary was considered to have developed from part of the mouth, thus, was not part of the brain.

\section{Abbreviations \\ ACTH: Adrenocorticotropic hormones; DCA: Desoxycorticosterone; \\ GAS: General adaptation syndrome; STH: Somatotropic hormone (growth} hormone)

\section{Acknowledgements \\ None}

Funding

This research received no specific grant from any funding agency in the public, commercial, or not-for-profit sectors.

Availability of data and materials

See the "References" section.

\section{Author's information}

The author completed a Ph.D. in medical psychology and a Master's in Public Health at Uniformed Services University of the Health Sciences in Bethesda, MD.

\section{Competing interests}

The author declares that she has no competing interests.

Received: 20 June 2016 Accepted: 7 November 2016

Published online: 30 November 2016

\section{References}

A new approach to tensions (1956), Newsweek, 3 December, pp. 55-58. American Heritage Dictionary of the English Language, 4th Edition (2006), New York, Houghton Mifflin Company.

Benison, S, Barger, AC, and Wolfe, EL. (1987), Walter B. Cannon: the life and times of a young scientist, Cambridge, MA, Belknap Press

Buff, I. E. (1959). The ballistocardiogram after a heavy meal: diagnostic value in patients with suspected coronary artery disease. The american journal of cardiology, 1, 111-112.

Campbell, M. (1963a). Main cause of increased death rate from diseases of the heart: 1920-1959. British medical journal, 2, 712

Campbell, M. (1963b). Death rate from diseases of the heart 1876 to 1959. British medical journal, 2, 528.

Campbell, M. (1964). The mortality rate from heart disease. American heart journal, 68, 1 
Cannon, W. B. (1932). The wisdom of the body. New York: Norton Publishers Chambers, W. M., \& Reiser, M. F. (1953). Emotional stress in the precipitation of congestive heart failure. Psychosomatic medicine, 15, 38-60.

Davis, F. W. (1959). The role of the ballistocardiograph in the diagnosis and management of patients with coronary heart disease: stress tests and the cigarette test. The american journal of cardiology, 1, 103-112.

Dawber, T. R. (1980). The Framingham study. The epidemiology of atherosclerotic disease. Cambridge: MA, Harvard University Press.

Dawber, T. R., Meadors, G. F., \& Moore, F. E. (1951). Epidemiological approaches to heart disease: the Framingham study. American journal of public health, 41, 279.

Dawber, T. R., Moore, F. E., Jr., \& Mann, G. V. (1957). Coronary heart disease in the Framingham study. American journal of public health, 47, 4-24.

Dublin, L. I., Spiegelman, M., \& Leland, R. G. (1947). Longevity and mortality of physicians. Post-graduate medical journal, 2, 188.

Fink, G. (1981). Has corticotropin-releasing factor finally been found? Nature, 294, 511-512.

Gordon, J. E. (1952). The twentieth century-yesterday, today and tomorrow (1920-). In F. H. Top (Ed.), The history of American epidemiology (pp. 114-160). St. Louis: Mosby Company.

Interview with a specialist: Dr. Edmund Jacobson. Tension: what it is and how you can relieve it (1957). U.S. News and World Report, 1 November, pp. 76-81.

Kristensen, T. S. (1999). Challenges for research and prevention in relation to work and cardiovascular diseases. Scandinavian journal of work and environmental health, 25(6), 550-557.

Lazarus, R. S. (1966). Psychological stress and the coping process. New York: McGraw-Hill.

Lichtman, J. H., Froelicher, E. S., Blumenthal, J. A., Carney, R. M., Doering, L. V., Frasure-Smith, N., Freedland, K. E., Jaffe, A. S., Leifheit-Limson, E. C., Sheps, D. S., Vaccarino, V., Wulsin, L., \& on behalf of the American Heart Association Statistics Committee of the Council on Epidemiology and Prevention and the Council on Cardiovascular and Stroke Nursing. (2014). Depression as a risk factor for poor prognosis among patients with acute coronary syndrome: systematic review and recommendations: a scientific statement from the American Heart Association. Circulation, 129, 1350-1369.

Macleod, J., \& Smith, G. D. (2002). Commentary: stress and the heart, 50 years of progress? International journal of epidemiology, 31, 1111-1113.

Marmot, M. G., Adelstein, A. M., Robinson, N., \& Rose, G. A. (1978). Changing social-class distribution of heart disease. British medical journal, 2, 1003-1006.

Mason, J. W. (1968). A review of psychoendocrine research on the pituitaryadrenal cortical system. Psychosomatic medicine, 30, 576-607.

Mason, J. W. (1975). A historical view of the stress field. Journal of human stress, 1, 6-12.

Moriyama, I., Krueger, D. E., \& Stamler, J. (1971). Cardiovascular diseases in the United States. Cambridge: MA, Harvard University Press.

Morris, J. N. (1975). Primary prevention of heart attack. Bulletin of the New York Academy of Medicine, 51, 62-64.

National Center for Health Statistics. (1998). Top leading causes of death, 1900 1998. Hyattsville: Centers for Disease Control and Prevention.

National Center for Health Statistics. (2006). Deaths: final data for 2003. Hyattsville: Centers for Disease Control and Prevention.

Platt, Robert (1951), Commentary (1951): coronary disease and modern stress, The Lancet, 51. Reprinted in (2002) International Journal of Epidemiology, 31, pp. 1108-1109.

President's Commission on Heart Disease, Cancer, and Stroke (1964-5), A national program to conquer heart disease, cancer and stroke, vol 1., Washington, D. C., Government Press Office, p. 29.

Ratcliff, J. D. (1955). Stress - the cause of all disease? Reader's digest, 66, 24-28.

Reader's Guide to Periodical Literature, March 1951-February 1953. Minneapolis: Wilson.

Reader's Guide to Periodical Literature, March 1953-February 1955. Minneapolis: Wilson.

Reader's Guide to Periodical Literature, March 1955-February 1957. Minneapolis: Wilson.

Reader's Guide to Periodical Literature, March 1957-February 1959. Minneapolis: Wilson.

Rosen, G. (1975). Preventive medicine in the United States 1900-1975: trends and interpretations. New York: Prodist.

Selye, H. (1956). The stress of life. New York: McGraw-Hill.
Selye, H. (1975). From dreams to discovery: on being a scientist. London: Ayer Company.

Selye, H. (1979). The stress of my life: a scientist's memoir. New York: Van Nostrand Reinhold.

Stewart, I. McD.G. (1950). "Coronary disease and modern stress", The Lancet, pp. 867-870. Reprinted in (2002). International journal of epidemiology, 31, 1103-1107.

Stress and strain (1954), Time, 18 January, pp. 66-67.

Wang, J. T., Hoffman, B., \& Blumenthal, J. A. (2011). Management of depression in patients with coronary heart disease: association, mechanisms, and treatment implications for depressed cardiac patients. Expert opinion on pharmacotherapy, 12, 85-98.

\section{Submit your manuscript to a SpringerOpen ${ }^{\circ}$ journal and benefit from:}

- Convenient online submission

- Rigorous peer review

- Immediate publication on acceptance

- Open access: articles freely available online

- High visibility within the field

- Retaining the copyright to your article

Submit your next manuscript at $>$ springeropen.com 